\title{
Titanium Dioxide/Activated Carbon Electrode with Polyurethane Binder for the Removal of Indium Ions via Capacitive Deionization
}

\author{
Clive H. Yen ${ }^{1}{ }^{(\mathbb{D},}$, Shun-Hsing Chuang ${ }^{2, *}$, Ren-Yi Huang ${ }^{3}$, Po-I Liu ${ }^{4}$, Min-Chao Chang ${ }^{4}$ and Ren-Yang Horng ${ }^{4}$ \\ 1 Department of Cosmetic Science, Providence University, Taichung City 43301, Taiwan; \\ kamehameha@pu.edu.tw \\ 2 Graduate Institute of Environmental Engineering, National Central University, Taoyuan City 32001, Taiwan \\ 3 Biomedical Technology and Device Research Laboratories, Industrial Technology Research Institute, \\ Hsinchu 310401, Taiwan; itri535479@itri.org.tw \\ 4 Material and Chemical Research Laboratories, Industrial Technology Research Institute, Hsinchu 310401, Taiwan; \\ borisliu@itri.org.tw (P.-I.L.); minchaochang@itri.org.tw (M.-C.C.); vincenthorng@itri.org.tw (R.-Y.H.) \\ * Correspondence: shchuang@ncu.edu.tw; Tel.: +886-3-422-7151 (ext. 34682)
}

check for

updates

Citation: Yen, C.H.; Chuang, S.-H.; Huang, R.-Y.; Liu, P.-I.; Chang, M.-C.; Horng, R.-Y. Titanium

Dioxide/Activated Carbon Electrode with Polyurethane Binder for the Removal of Indium Ions via Capacitive Deionization. Processes 2021, 9, 1427. https://doi.org/ $10.3390 /$ pr9081427

Academic Editor: Junjie Shen

Received: 12 July 2021

Accepted: 14 August 2021

Published: 18 August 2021

Publisher's Note: MDPI stays neutral with regard to jurisdictional claims in published maps and institutional affiliations.

Copyright: (c) 2021 by the authors. Licensee MDPI, Basel, Switzerland. This article is an open access article distributed under the terms and conditions of the Creative Commons Attribution (CC BY) license (https:/ / creativecommons.org/licenses/by/ $4.0 /)$.

\begin{abstract}
The process of removing indium ions from aqueous solutions by applying capacitive deionization (CDI) is reported in this manuscript. First, a modified carbon material was prepared by incorporating titanium dioxide $\left(\mathrm{TiO}_{2}\right)$ into activated carbon (AC). A microwave-assisted ionothermal synthesis (MAIS) method was used to produce evenly distributed nanostructured anatase $\mathrm{TiO}_{2}$ on the surface of AC. A polyurethane (PU) elastomer was then synthesized as the binder material instead of using conventional polyvinylidene fluoride (PVDF). By combining the aforementioned materials, a MAIS $\mathrm{TiO}_{2}$ /AC-PU electrode was synthesized and applied to CDI tests. Scanning electron microscopy (SEM) was used to characterize the size and dispersion of the composites. For electrochemical properties, cyclic voltammetry $(\mathrm{CV})$ and electrochemical impedance spectroscopy (EIS) were used to analyze the synthesized electrode. The performance of the prepared electrode during the CDI process was tested in different concentrations of indium solutions. It was discovered that the indium removal efficiency can be as high as $84 \%$ in 1 and 5 ppm of indium solutions.
\end{abstract}

Keywords: capacitive deionization; indium removal; microwave-assisted ionothermal synthesis; polyurethane; adsorption

\section{Introduction}

Capacitive deionization (CDI) is a technology known for removing charged ions from water [1-3]. Ideally, when the charged ions in the aqueous solution pass by the electrodes, only electrosorption of the ions to the electrodes occurs without any additional redox reaction. Therefore, when the potential of the electrodes is reversed, desorption of the ions takes place, leaving a fresh set of electrodes for reuse. The major application of CDI has always been desalination, especially for brackish water. However, CDI has gained much popularity recently due to the development of new nanosize carbon electrode materials which could greatly enhance desalination efficiency [4]. Other than salt removal, more applications have been found using CDI, including biomass hydrolyzate and heavy metal removal [5]. Huang et al. reported the removal of cadmium, lead, and chromium from water using CDI and they discovered that the applied voltage can influence the removal efficiency, and each metal had a different optimum applied voltage [6]. From their results, chromium and lead had a similar removal efficiency around $80 \%$, whereas cadmium had only a low removal efficiency of $40 \%$. Another study by Huang's group reported the removal of copper ions using CDI [7]. Their research showed that the removal of copper ions did not interfere with salt ions, natural organic matter, or reactive silica dissolved in the aqueous solution. Furthermore, a recent study by Liu et al. demonstrated 
a wide application for CDI by removing metals including lead, copper, iron, cadmium, cobalt, nickel, zinc, magnesium, and calcium [8]. Highly porous N-doped graphene nanosheets were used as the electrode material, and the removal efficiencies were more than $90 \%$ for all the metal ions. In a recent article, recovery of indium ions was reported by using CDI technology [9]. The effectiveness of this recovering process was due to the acidic environment in the solution. The porous activated carbon electrode provided sufficient spacing for the cations, including $\mathrm{In}^{3+}$ and $\mathrm{H}^{+}$, to be electrosorbed in their capacity. According to the report, the deionization capacity of $\operatorname{~In~}^{3+}$ could be as high as $7.95 \mathrm{mg} / \mathrm{g}$ under optimum conditions. Therefore, the authors suggested that this process showed high potential in recovering indium ions from acidic solutions.

To the best of our knowledge, other than the aforementioned article, there is scarce literature on the removal of indium ions from aqueous solutions using CDI. Indium is a less abundant metal and can be found as a minor component in many mineral ores, such as zinc and copper ores. The major application of indium is for making indium tin oxide (ITO), which is a transparent conducting oxide widely used in flat panel displays and other electronic devices. Therefore, indium is often contained in the wastewater from the optoelectronics and semiconductor industry. Many reports about recovering or removing indium from the ITO etching wastewater [10-13]. Commercially, the main treatment for indium in ITO etching wastewater was by dilution, since after dilution, the indium concentration meets the effluent standards [14]. This method was considered simple and relatively inexpensive. However, it could consume a large volume of freshwater, which is currently a valuable natural resource. Therefore, alternative methods for removing indium from wastewater are still needed to be introduced.

In order to enhance the removal efficiency, two approaches were taken to modify the conventional CDI electrode. The first approach was to incorporate titanium dioxide into the surface and pores of the activated carbon. According to the literature, $\mathrm{TiO}_{2}$ has some special affinity with indium ions [15]. Zhang et al. discovered that $\mathrm{TiO}_{2}$ had a high adsorption efficiency of trace indium ions in $\mathrm{pH} 3.5-4.0$ and a high desorption efficiency when $\mathrm{pH}$ was lower than 1.5 [16]. They also discovered that anatase $\mathrm{TiO}_{2}$ had a higher adsorption efficiency for indium than rutile $\mathrm{TiO}_{2}$. Hang et al. studied the adsorption of indium on nanosize $\mathrm{TiO}_{2}$ [17]. They also discovered that $\mathrm{TiO}_{2}$ had a high adsorption ratio and capacity to indium ions. Therefore, titanium dioxide and activated carbon composite $\left(\mathrm{TiO}_{2} / \mathrm{AC}\right)$ could have a high potential for efficient adsorption-desorption of indium ions. The other approach was to substitute the binder material since the binder of the electrode could also be influential to the electrode performance. One of the most widely used binder materials is polyvinylidene fluoride (PVDF) [18]. It is a hydrophobic polymer and can maintain the consistency of the carbon electrodes. However, cracking of the electrodes was often found when using the PVDF binder electrodes. Therefore, a polyurethane (PU) binder with stronger mechanical strength was developed. Less cracking was found when using CDI, and the electrode performance was maintained similar to the PVDF ones. In this manuscript, a microwave-assisted ionothermal synthesized (MAIS) nanostructured anatase titanium oxide/activated carbon composite was mixed with a polyurethane elastomer to prepare a MAIS $\mathrm{TiO}_{2} / \mathrm{AC}-\mathrm{PU}$ electrode. The physical and electrochemical properties of the MAIS $\mathrm{TiO}_{2}$ / AC-PU electrode were characterized. Applying the MAIS $\mathrm{TiO}_{2}$ / AC-PU electrode for removing indium from the solution was tested, and the results indicated that

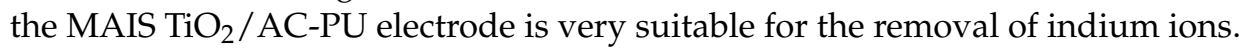

\section{Materials and Methods}

\subsection{Instrumentation}

Inductively coupled plasma atomic emission spectroscopy (ICP-AES) was performed by iCAP 6300 (Thermo Fisher Scientific; Waltham, MA, USA) to analyze the concentration of the indium solutions. Scanning electron microscopy (SEM) was performed by JEOL JSE-6500F (Tokyo, Japan). The surface area and pore volume of the carbon material were measured by NOVA4000e and Autosorp MP1 instruments (Quantachrome; Boynton Beach, 
FL, USA). The Brunauer-Emmet-Teller (BET) method was used for analyzing the surface area, and the Barrett-Joyner-Halenda (BJH) model was used for determining the pore size and volume. Transmission electron microscopy (TEM) coupled with energy dispersive spectroscopy (EDS) were performed by a PHILIPS CM100 to measure particle size and metal content.

\subsection{Preparation of Polyurethane Elastomer}

The detailed synthesis procedure and material characterization of the polyurethane (PU) elastomer are provided in a previous report [19]. Polytetramethylene glycol (PTMEG; number average molecular weight $=2000$ ) was purchased from Lidye Chemical, Taiwan. Glycerin monostearate diol (GMS) was purchased from First Chemical Manufacture, Taiwan. 2,4-toluene diisocyanate (TDI) was purchased from Tokyo Chemical Industry, Japan. $\mathrm{N}$-methyl-2-pyrrolidone (NMP) was purchased from Sigma-Aldrich. All chemicals were used as received. In brief, PTMEG was first mixed with GMS and then TDI at $70{ }^{\circ} \mathrm{C}$ in NMP solvent to produce the prepolymer of PU. Followed by the moisture-curing step, the free isocyanate groups of the prepolymer reacted with water molecules. After complete reaction, the prepolymer transformed into a PU elastomer with a high molecular weight.

\subsection{Microwave-Assisted Ionothermal Synthesis of $\mathrm{TiO}_{2} / \mathrm{AC}$ Composite}

The detailed synthesis procedure and material characterization of the $\mathrm{MAIS}_{\mathrm{TiO}} / \mathrm{AC}$ composite are provided in a previous report [20]. Activated carbon (AC) was purchased from Formosa Plastics Corporation (Taiwan). Titanium tetraisopropoxide (TIP), isopropanol, and 1-butyl-3-methylimidazolium tetrafluoroborate $\left([\mathrm{Bmim}]^{+}\left[\mathrm{BF}_{4}\right]^{-}\right)$ionic liquid were all purchased from Merck and used as received. In brief, MAIS contains two stages: a controlled sol-gel reaction and a subsequent ionic liquid-inducing crystallization. In a typical trial, $0.5 \mathrm{~g}$ of TIP, $2 \mathrm{~g}$ of $\mathrm{AC}$, and $0.4 \mathrm{~g}$ of ionic liquid $[\mathrm{Bmim}]^{+}\left[\mathrm{BF}_{4}\right]^{-}$were mixed together with $200 \mathrm{~mL}$ of isopropanol using ultrasonication for dispersion. A small amount of water (less than $1 \mathrm{~g}$ ) was added to the mixture for a sol-gel reaction. Afterward, the mixture was transferred into a microwave system with a power of $800 \mathrm{~W}$, a frequency of $2.45 \mathrm{GHz}$ for $30 \mathrm{~min}$ with reflux. After microwaving, the mixture was filtered and dried in an oven at $70{ }^{\circ} \mathrm{C}$.

For crystallization in the second stage, as in a typical trial, $2 \mathrm{~g}$ of the dried sample powder from the first stage was mixed together with $80 \mathrm{~mL}$ of isopropanol, $7.2 \mathrm{~g}$ of ionic liquid $[\mathrm{Bmim}]^{+}\left[\mathrm{BF}_{4}\right]^{-}$and $9.6 \mathrm{~g}$ of water using ultrasonication. The mixture was then transferred into a microwave system with the same conditions mentioned above for $1 \mathrm{~h}$. After microwaving, the mixture was again filtered and dried in an oven at $70^{\circ} \mathrm{C}$. The synthesized $\mathrm{TiO}_{2} / \mathrm{AC}$ composite had $8.2 \mathrm{wt} \%$ of $\mathrm{TiO}_{2}$. The percent loading of $\mathrm{TiO}_{2}$ in $\mathrm{TiO}_{2} / \mathrm{AC}$ composite was determined by conducting thermogravimetric analysis (TGA) (Perkin Elmer-TAC7/DX, Thermal Analysis Controller). While measuring the sample mass, the sample was heated from 30 to $800{ }^{\circ} \mathrm{C}$ to burn off any carbon-based material. The heating rate was $20^{\circ} \mathrm{C} / \mathrm{min}$. The weight difference between the coated and uncoated samples was used to determine the percent loading of the $\mathrm{TiO}_{2}$. Moreover, the $\mathrm{TiO}_{2}$ had a particle size in a range of 7-12 $\mathrm{nm}$, which was observed by TEM [21].

\subsection{Fabrication of the Electrodes}

Graphite powder (particle size: 3.5 micron) was purchased from Emaxwin, Taiwan. Polyvinylidene fluoride (PVDF) was purchased from Sigma-Aldrich. In a typical trial, the $\mathrm{TiO}_{2} / \mathrm{AC}$ composite, the binder (PU elastomer or PVDF), and graphite were mixed together in NMP solvent with a mass ratio of 8: 1: 1 . After carefully stirring the mixture for $24 \mathrm{~h}$, the slurry mixture was cast onto a titanium board by a doctor blade technique with a wet thickness of 300 micron. The coated electrode was then dried in an oven at $120^{\circ} \mathrm{C}$ for $4 \mathrm{~h}$. 


\subsection{Electrochemical Characterization}

Indium nitrate $\left(\mathrm{In}\left(\mathrm{NO}_{3}\right)_{3} ; 99.9 \%\right)$ was purchased from Merck. Sodium chloride $(\mathrm{NaCl})$ was purchased from Shimadzu. Cyclic voltammetry (CV) and electrochemical impedance spectroscopy (EIS) were conducted by an electrochemical workstation (CHI 614D; CH Instruments) and in a three-compartment cell. The capacitance of the prepared electrodes was determined by $\mathrm{CV}$ using an $\mathrm{Ag} / \mathrm{AgCl}$ reference electrode, a platinum wire counter electrode, and a $0.5 \mathrm{M} \mathrm{NaCl}$ electrolyte. The scan rate was $10 \mathrm{mV} / \mathrm{s}$ from a potential range of $-0.5 \mathrm{~V}-0.5 \mathrm{~V}$, and the capacitance was measured accordingly. On the other hand, the EIS measurements were organized using an alternating current perturbation amplitude of $5 \mathrm{mV}$ around the equilibrium potential of $0 \mathrm{~V}$. The frequency range was from $1 \mathrm{mHz}$ to $100 \mathrm{kHz}$.

\subsection{Performance}

The detailed CDI apparatus setup is illustrated in a previous report [20]. In brief, a DC power supply was connected to a CDI cell equipped with a peristaltic pump. The sample feed was pumped to pass through the CDI cell and back to the feed for measurements and data analysis. The electrodes in the CDI cell were placed on both sides of the silicon packing and kept parallel with $0.2 \mathrm{~cm}$ apart. The electrode's total opening area was $80 \mathrm{~cm}^{2}$ $(5 \mathrm{~cm} \times 8 \mathrm{~cm} \times 2)$. In a typical trial, a sample solution of $100 \mathrm{~mL}$ was pumped into the CDI cell with an influent rate of $12 \mathrm{~mL} / \mathrm{min}$. A potential of $0.7 \mathrm{~V}$ was applied for a total adsorption time of $156 \mathrm{~min}$. The $\mathrm{pH}$ value of the solution was monitored throughout the experiment. After the experiment was finished, the indium concentration was analyzed by ICP-AES.

For the calculation of the electrosorption capacity, the following equation is used:

$$
\text { Electrosorption capacity }(\mathrm{mg} / \mathrm{g})=\left(C_{0}-C_{e}\right) V / m
$$

where $C_{0}$ is the initial concentration of iridium, $C_{e}$ is the equilibrium concentration for iridium, $V$ is the volume of the iridium solution, and $m$ is the mass of the AC electrode.

\section{Results}

\subsection{Characterization of the Electrode Materials}

A petroleum coke-based activated carbon was selected as the AC material for our experiments due to its high surface area and large mesopore volume $(2-50 \mathrm{~nm})$. Table 1 shows the characteristics of the petroleum coke-based activated carbon from BET and BJH analysis. The mesopores in the activated carbon may help adsorb more ions due to the larger surface area. Additionally, some reports discovered that micropores are also very efficient for ion adsorption in CDI, and the AC material provides some [22,23].

Table 1. Characteristics of the petroleum coke-based activated carbon.

\begin{tabular}{ccccc}
\hline $\begin{array}{c}\text { Specific Surface } \\
\text { Area }\end{array}$ & $\begin{array}{c}\text { Total Pore } \\
\text { Volume }\end{array}$ & $\begin{array}{c}\text { Micropore } \\
\text { Volume }(<\mathbf{2} \mathbf{n m})\end{array}$ & $\begin{array}{c}\text { Mesopore Volume } \\
(\mathbf{2}-50 \mathbf{n m})\end{array}$ \\
\hline $\mathrm{AC}$ & $2715 \mathrm{~m}^{2} / \mathrm{g}$ & $1.55 \mathrm{~cm}^{3} / \mathrm{g}$ & $0.06 \mathrm{~cm}^{3} / \mathrm{g}$ & $1.10 \mathrm{~cm}^{3} / \mathrm{g}$ \\
\hline
\end{tabular}

The MAIS $\mathrm{TiO}_{2}$ / AC-PU electrode was successfully prepared, and its scanning electron microscopy (SEM) images, together with the images of AC-PU, are shown in Figure 1. Both electrodes had similar SEM images, which were mostly showing the activated carbon and graphite particles. The $\mathrm{TiO}_{2}$ particles (7-12 nm) and $\mathrm{AC}$ were well-mixed with the PU binder and distributed evenly in the SEM images. 

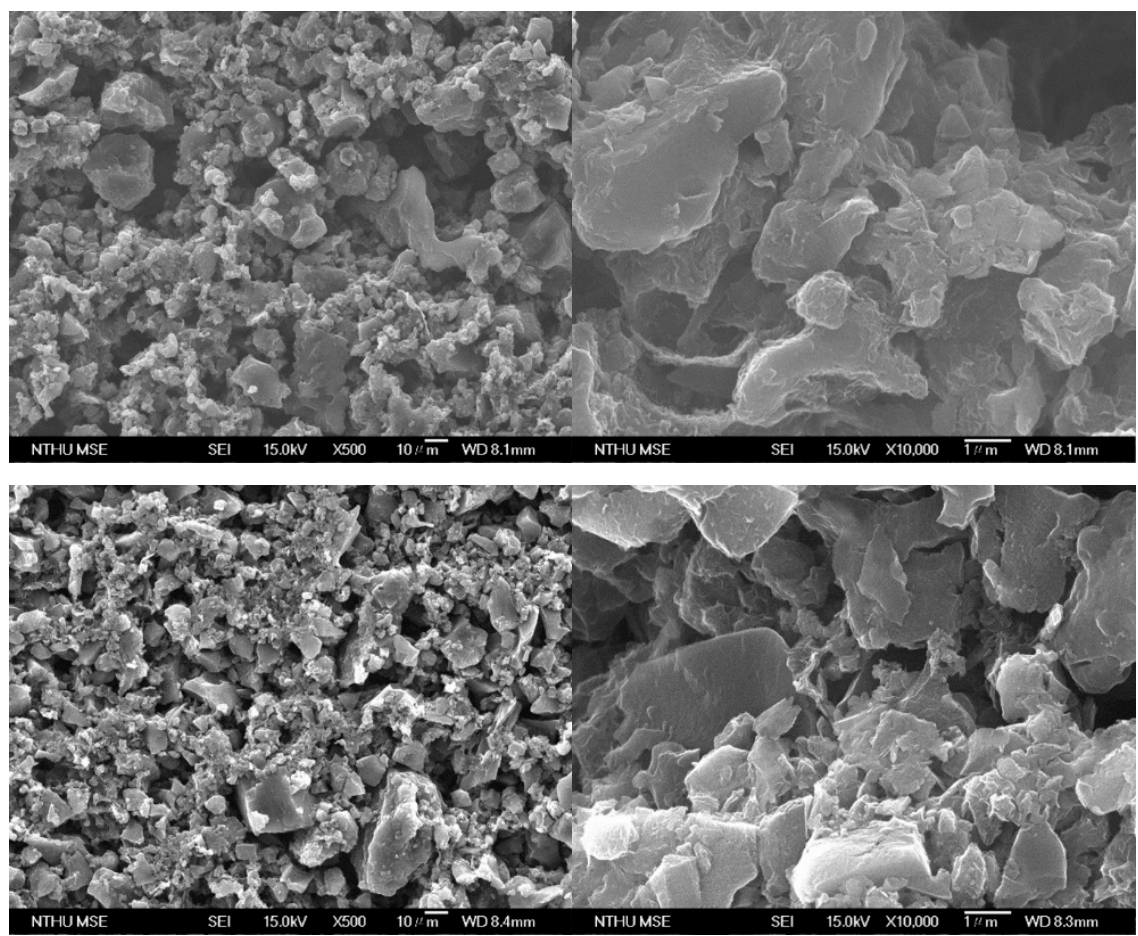

Figure 1. Scanning electron microscopy (SEM) of the electrodes: top left is AC-PU $(\times 500)$; top right is AC-PU $(\times 10,000)$; bottom left is MAIS $\mathrm{TiO}_{2} / \mathrm{AC}-\mathrm{PU}(\times 500)$, and bottom right is $\mathrm{MAIS} \mathrm{TiO}_{2} / \mathrm{AC}$-PU $(\times 10,000)$. (For each image, scale bars on the left are 10 microns and on the right are 1 micron).

\subsection{Cyclic Voltammetry Analysis of the Electrodes}

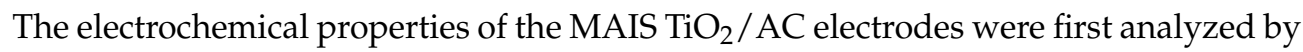
cyclic voltammetry $(\mathrm{CV})$, and their $\mathrm{CV}$ plots and average capacitance are shown in Figure 2 and Table 2, respectively. The CV plots were conducted in a $0.5 \mathrm{M} \mathrm{NaCl}$ aqueous electrolyte at a scan rate of $10 \mathrm{mV} / \mathrm{s}$, and the plots showed rectangular-like curves attributable to an ideal double-layer capacitive behavior for the electrodes. Two activated carbon electrodes without incorporating $\mathrm{TiO}_{2}$ (AC-PU and AC-PVDF) were also tested for comparison. The results showed that the $\mathrm{MAIS} \mathrm{TiO}_{2} / \mathrm{AC}$ electrodes had higher average capacitance than those without $\mathrm{TiO}_{2}$; this could be due to the dielectric constant of $\mathrm{TiO}_{2}$ (86-173), which is approximately an order of magnitude higher than those of activated carbon and graphite (10-15) [24]. In our previous study [20,21], the increase in electrode capacitance after $\mathrm{TiO}_{2}$ modification is due to the deposition of anatase $\mathrm{TiO}_{2}$ with a suitable amount of $\mathrm{Ti}-\mathrm{OH}$. Higher amounts of the Ti-OH can improve the surface wetting ability of the AC electrode, thereby facilitating the access ability of solution ions to the surface of the AC electrode and a higher uptake capacity of the ions on the electrode. Meanwhile, the resistivity measurement also indicates that the nanosized $\mathrm{TiO}_{2}$ lowers the resistivity of electrode material prepared by our MAIS synthesis method. Since the average capacitance of these electrodes is high, they all are suitable materials for being CDI electrodes.

\subsection{Electrochemical Impedance Spectroscopy Analysis of the Electrodes}

Electrochemical impedance spectroscopy (EIS) was also applied to measure some of the electrochemical properties of the electrodes, and the Nyquist plots are shown in Figure 3. In Nyquist plots, the semicircle diameter can be assigned as the polarization resistance or, in other words, the contact resistance. Therefore, a shorter diameter for the semicircle is preferred since lower contact resistance is beneficial for electrical conduction. From our results, the MAIS $\mathrm{TiO}_{2}$ / AC-PU and AC-PU electrodes had very similar semicircle diameters. This result indicated that incorporating $\mathrm{TiO}_{2}$ into the activated carbon only had 


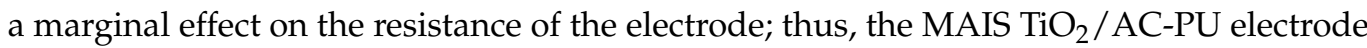
could work just as efficiently as the AC-PU electrode.

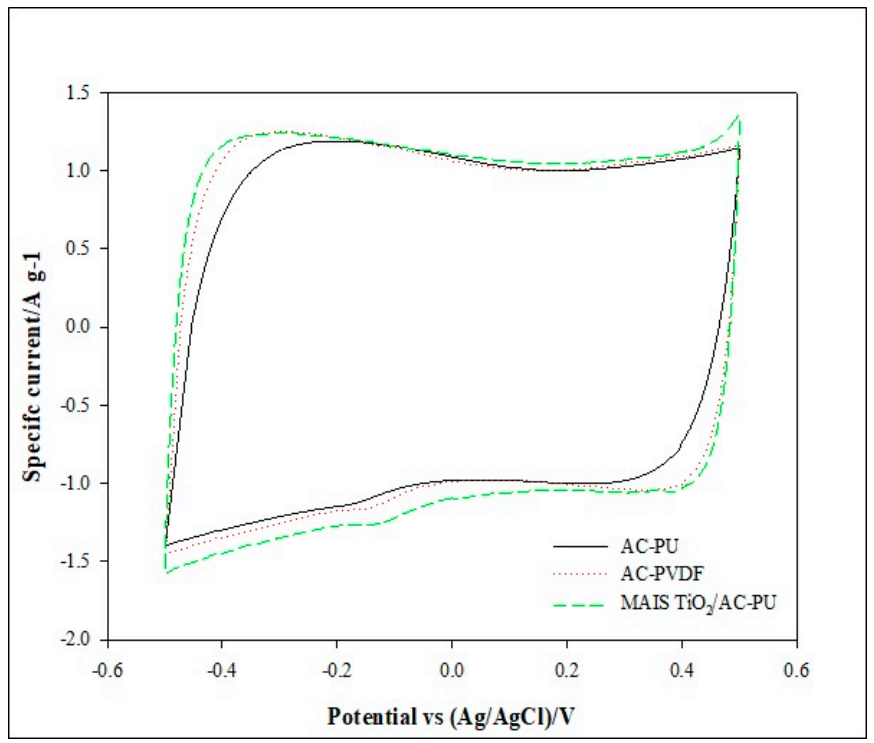

Figure 2. Cyclic voltammetry (CV) plots of different electrodes in $0.5 \mathrm{M} \mathrm{NaCl}$ aqueous electrolyte at a scan rate of $10 \mathrm{mV} / \mathrm{s}$.

Table 2. The average capacitance of the different electrodes ${ }^{1}$.

\begin{tabular}{cc}
\hline CDI Electrode & Average Capacitance (F/g) \\
\hline AC-PU & $122.4 \pm 4.3$ \\
AC-PVDF & $129.6 \pm 2.3$ \\
MAIS TiO $_{2} /$ AC-PU & $135.2 \pm 4.0$ \\
\hline
\end{tabular}

${ }^{1}$ Electrolyte: $0.5 \mathrm{M} \mathrm{NaCl}$.
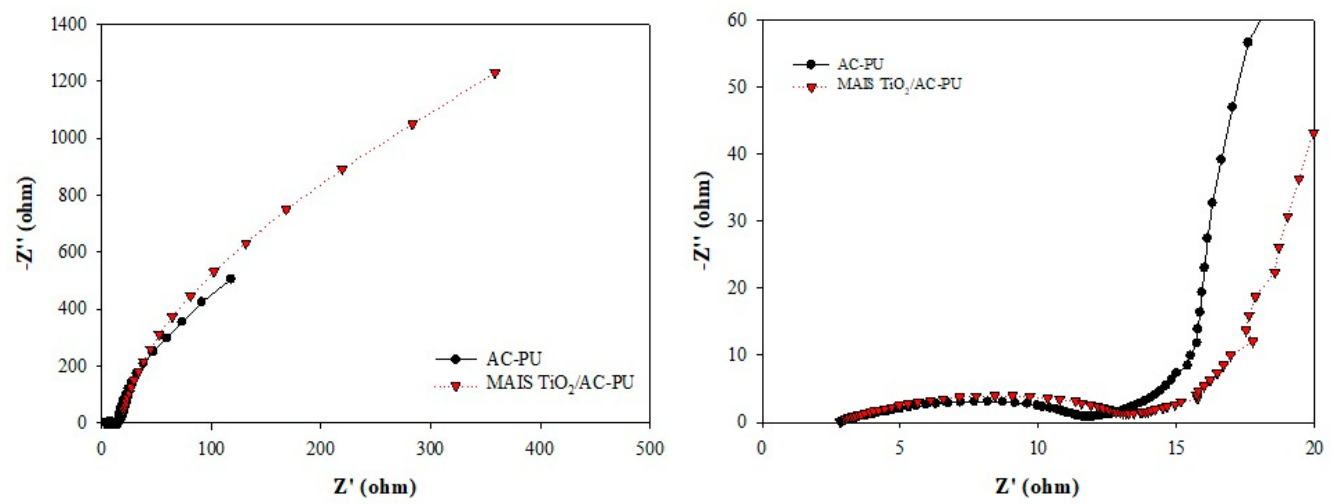

Figure 3. Nyquist plots for the electrodes: left is whole region; right is close-up of the near region.

The Bode plots for the different electrodes are shown in Figure 4, and the resistance and capacitive behaviors of the electrodes can also be compared. A phase angle closer to $-90^{\circ}$ indicates that the electrode has higher capacitance, whereas a phase angle closer to $0^{\circ}$ signifies that the electrode has a higher resistance. From our results, the maximum phase angles (closer to $-90^{\circ}$ ) were observed at a lower frequency range for both electrodes with

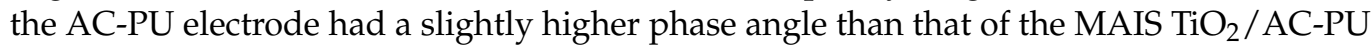
electrode. Therefore, the results from the Bode and Nyquist plots confirmed with each other that both kinds of electrodes were fabricated well enough for CDI applications. 


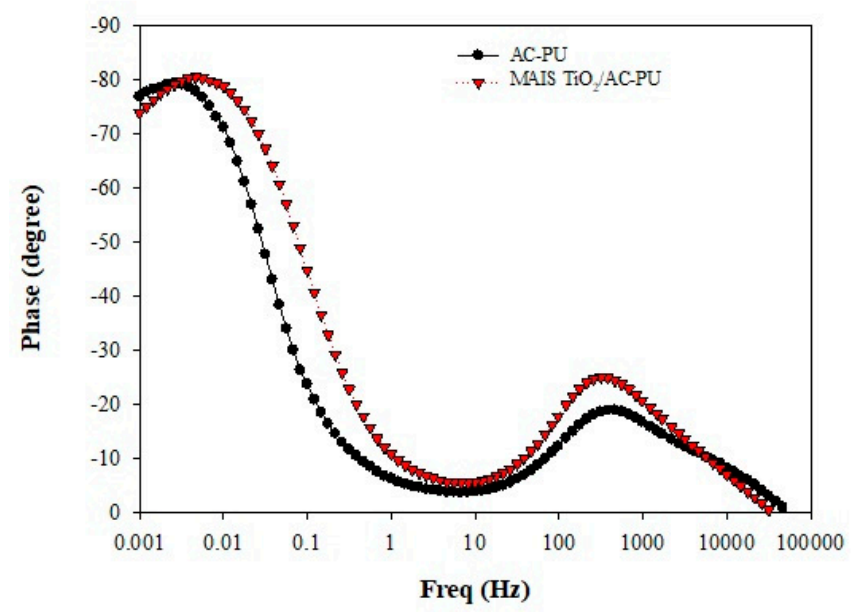

Figure 4. Bode plots for the electrodes.

\subsection{Performance of the MAIS $\mathrm{TiO}_{2} / A C-P U$ Electrode}

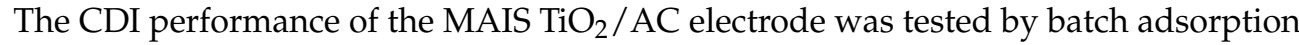
experiments, and the indium removal efficiency and electrosorption capacity was calculated

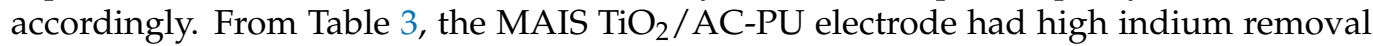
efficiency (about $80 \%$ or more) when the initial indium concentration was in the range of 1-10 ppm. As the initial concentration of indium increased, the removal efficiency decreased since the adsorption sites in the electrode material were limited. On the other hand, the electrosorption capacity increased with the increase in the initial concentration of indium. However, the electrosorption capacity reached a plateau in higher concentration conditions, and this adsorption phenomenon was speculated to follow the Langmuir adsorption model during lower concentrations (1-10 ppm) and the Freundlich model during higher concentrations ( $>10 \mathrm{ppm})$. Also, the results are quite comparable with a relatively similar work in the literature by Khan et al. [25]. In their study, a carbon nanotube-PU composite was used as a CDI electrode to remove lead, a post-transition metal resembling indium, from an aqueous solution. The carboxyl group on the carbon nanotube reacted with the amide group of $\mathrm{PU}$, and the dispersibility of the carbon nanotube increased in the solution, which also improved the lead adsorption. Nevertheless, the lead removal rate in neutral and acidic solutions was reported to be approximately $97 \%$ and $85 \%$, respectively.

Table 3. Removal efficiency of indium ions using different electrode materials in batch experiments of CDI.

\begin{tabular}{ccccc}
\hline Electrode Type & Initial Concentration (ppm) & Final Concentration (ppm) & $\begin{array}{c}\text { Final pH } \\
\text { pemoval }\end{array}$ & $\begin{array}{c}\text { Electrosorption } \\
\text { Capacity (mg/g) }\end{array}$ \\
\hline Efficiency (\%)
\end{tabular}

${ }^{1}$ All initial $\mathrm{pH}=3.5$.

AC-PU and AC-PVDF, which are AC electrodes without $\mathrm{TiO}_{2}$, were compared with the CDI tests. However, precipitation of indium and its hydroxide occurred during the $\mathrm{CDI}$ process. Moreover, the $\mathrm{pH}$ of the solutions increased rapidly and even changed from acidic into weak basic for both AC-PU and AC-PVDF electrodes. It should be noted that precipitation can be avoided when the initial $\mathrm{pH}$ is less than 3 for the AC-PU and AC-PVDF electrodes. However, a stronger acidic solution would be more difficult to handle due to 
safety issues. According to the Pourbaix diagram, or potential/pH diagram, in an acidic solution with $0.7 \mathrm{~V}$, most indium ions are in the form of $\operatorname{In}^{3+}$ while some $[\operatorname{In}(\mathrm{OH})]^{2+}$ may also be formed near neutral conditions [26]. In a basic solution with $0.7 \mathrm{~V}$, the indium starts to form $\operatorname{In}(\mathrm{OH})_{3}$ and precipitate. If precipitation of indium and its hydroxide occurred during the CDI process, it might require extra treatments to remove the precipitation. Generally, the $\mathrm{pH}$ value should be stable throughout the whole CDI process [7]. In our

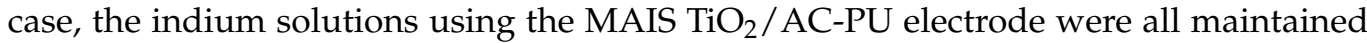
at an acidic $\mathrm{pH}$ ranging from 3.5 to 5.6, and no precipitation or hydrolysis was observed during the process. It is speculated that the $\mathrm{TiO}_{2}$ particles may have stabilized the indium ions during the $\mathrm{CDI}$ adsorption process since $\mathrm{TiO}_{2}$ is reported to have special electrical and chemical properties when doping indium [27-29]. The stabilization of $\mathrm{TiO}_{2}$ to indium may

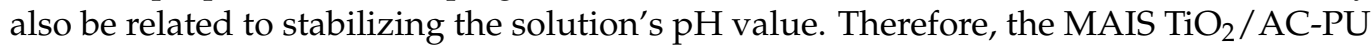
electrode is suitable for indium removal using CDI.

\section{Conclusions}

The MAIS $\mathrm{TiO}_{2}$ / AC-PU demonstrated in this report that it could be a very effective electrode for indium removal using CDI. The PU binder can help improve the removal efficiency, and it can be a good alternative to the conventional PVDF binder. Moreover,

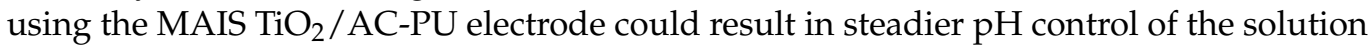
than using a conventional electrode; this could help prevent precipitation of the indium. It is very promising to apply CDI to remove indium from industrial wastewater as this report's removal efficiency could be as high as $84 \%$. Based on our results, improving the selectivity and efficiency of the electrode is critical for CDI applications, and it will be our priority task in the near future.

Author Contributions: Conceptualization, S.-H.C. and M.-C.C.; methodology, R.-Y.H. (Ren-Yang Horng) and M.-C.C.; formal analysis, P.-I.L. and R.-Y.H. (Ren-Yang Horng); investigation, C.H.Y., M.-C.C. and S.-H.C.; data curation, P.-I.L. and R.-Y.H. (Ren-Yang Horng); writing-original draft preparation, C.H.Y. and M.-C.C.; writing-review and editing, C.H.Y. and S.-H.C.; project administration, R.-Y.H. (Ren-Yi Huang). All authors have read and agreed to the published version of the manuscript.

Funding: This research was funded by the Ministry of Science and Technology, grant number 101-2221-E-324-013-MY3 and by TPC-(061)-(090001901).

Institutional Review Board Statement: Not applicable.

Informed Consent Statement: Not applicable.

Data Availability Statement: Not applicable.

Acknowledgments: The authors would like to thank L.C. Chung of ITRI for the research support.

Conflicts of Interest: The authors declare no conflict of interest.

\section{References}

1. Porada, S.; Zhao, R.; van der Wal, A.; Presser, V.; Biesheuvel, P.M. Review on the science and technology of water desalination by capacitive deionization. Prog. Mater. Sci. 2013, 58, 1388-1442. [CrossRef]

2. AlMarzooqi, F.A.; Al Ghaferi, A.A.; Saadat, I.; Hilal, N. Application of capacitive deionisation in water desalination: A review. Desalination 2014, 342, 3-15. [CrossRef]

3. Zhang, X.; Zuo, K.; Zhang, X.; Zhang, C.; Liang, P. Selective ion separation by capacitive deionization (CDI) based technologies: A state-of-the-art review. Environ. Sci. Water Res. Technol. 2020, 6, 243-257. [CrossRef]

4. Thamilselvan, A.; Nesaraj, A.S.; Noel, M. Review on carbon-based electrode materials for application in capacitive deionization process. Int. J. Environ. Sci. Technol. 2016, 13, 2961-2976. [CrossRef]

5. Suss, M.E.; Porada, S.; Sun, X.; Biesheuvel, P.M.; Yoon, J.; Presser, V. Water desalination via capacitive deionization: What is it and what can we expect from it? Energy Environ. Sci. 2015, 8, 2296-2319. [CrossRef]

6. Huang, Z.; Lu, L.; Cai, Z.; Ren, Z.J. Individual and competitive removal of heavy metals using capacitive deionization. J. Hazard. Mater. 2016, 302, 323-331. [CrossRef] [PubMed]

7. Huang, S.Y.; Fan, C.S.; Hou, C.H. Electro-enhanced removal of copper ions from aqueous solutions by capacitive deionization. J. Hazard. Mater. 2014, 278, 8-15. [CrossRef] 
8. Liu, L.; Guo, X.; Tallon, R.; Huang, X.; Chen, J. Highly porous N-doped graphene nanosheets for rapid removal of heavy metals from water by capacitive deionization. Chem. Commun. 2017, 53, 881-884. [CrossRef]

9. Shen, Y.Y.; Wu, S.W.; Hou, C.H. Exploring the electrosorption selectivity and recovery of indium ions with capacitive deionization in acidic solution. J. Colloid Interface Sci. 2021, 586, 819-829. [CrossRef]

10. Liu, H.M.; Wu, C.C.; Lin, Y.H.; Chiang, C.K. Recovery of indium from etching wastewater using supercritical carbon dioxide extraction. J. Hazard. Mater. 2009, 172, 744-748. [CrossRef] [PubMed]

11. Swain, B.; Mishra, C.; Hong, H.S.; Cho, S.S. Treatment of indium-tin-oxide etching wastewater and recovery of In, Mo, Sn and Cu by liquid-liquid extraction and wet chemical reduction: A laboratory scale sustainable commercial green process. Green Chem. 2015, 17, 4418-4431. [CrossRef]

12. Hasegawa, H.; Rahman, I.M.M.; Umehara, Y.; Sawai, H.; Maki, T.; Furusho, Y.; Mizutani, S. Selective recovery of indium from the etching waste solution of the flat-panel display fabrication process. Microchem. J. 2013, 110, 133-139. [CrossRef]

13. Chou, W.S.; Shen, Y.H.; Yang, S.J.; Hsiao, T.C.; Huang, L.F. Recovery of indium from the etching solution of indium tin oxide by solvent extraction. Environ. Prog. Sustain. Energy 2016, 35, 758-763. [CrossRef]

14. Hsu, K.U.; Hu, Y.T.; Chu, C.P.; Chung, Y.R. Current investigation and control of new pollutants in wastewater and recycled water (translated from Chinese). Sinotech Eng. 2014, 123, 3-15.

15. Atanacio, A.J.; Bak, T.; Nowotny, J. Effect of indium segregation on the surface versus bulk chemistry for indium-doped $\mathrm{TiO}_{2}$. ACS Appl. Mater. Interfaces 2012, 4, 6626-6634. [CrossRef]

16. Zhang, L.; Wang, Y.; Guo, X.; Yuan, Z.; Zhao, Z. Separation and preconcentration of trace indium(III) from environmental samples with nanometer-size titanium dioxide. Hydrometallurgy 2009, 95, 92-95. [CrossRef]

17. Hang, Y.; Qin, Y.; Jiang, Z.; Hu, B. Study on the adsorption behavior of Ga, In and Tl on nanometer-size titanium dioxide by ICP-AES. Spectrosc. Spect. Anal. 2005, 25, 1131-1134.

18. Choi, J.Y.; Choi, J.H. A carbon electrode fabricated using a poly(vinylidene fluoride) binder controlled the Faradaic reaction of carbon powder. J. Ind. Eng. Chem. 2010, 16, 401-405. [CrossRef]

19. Fang, C.H.; Liu, P.I.; Chung, L.C.; Shao, H.; Ho, C.H.; Chen, R.S.; Fan, H.T.; Liang, T.M.; Chang, M.C.; Horng, R.Y. A flexible and hydrophobic polyurethane elastomer used as binder for the activated carbon electrode in capacitive deionization. Desalination 2016, 399, 34-39. [CrossRef]

20. Liu, P.I.; Chung, L.C.; Shao, H.; Liang, T.M.; Horng, R.Y.; Ma, C.C.M.; Chang, M.C. Microwave-assisted ionothermal synthesis of nanostructured anatase titanium dioxide/activated carbon composite as electrode material for capacitive deionization. Electrochim. Acta 2013, 96, 173-179. [CrossRef]

21. Liu, P.I.; Chung, L.C.; Ho, C.H.; Shao, H.; Liang, T.M.; Horng, R.Y.; Chang, M.C.; Ma, C.C.M. Effects of activated carbon characteristics on the electrosorption capacity of titanium dioxide/activated carbon composite electrode materials prepared by a microwave-assisted ionothermal synthesis method. J. Colloid Interface Sci. 2015, 446, 352-358. [CrossRef] [PubMed]

22. Porada, S.; Borchardt, L.; Oschatz, M.; Bryjak, M.; Atchison, J.S.; Keesman, K.J.; Kaskel, S.; Biesheuvel, P.M.; Presser, V. Direct prediction of the desalination performance of porous carbon electrodes for capacitive deionization. Energy Environ. Sci. 2013, 6, 3700-3712. [CrossRef]

23. Zhao, S.; Yan, T.; Wang, Z.; Zhang, J.; Shi, L.; Zhang, D. Removal of NaCl from saltwater solutions using micro/mesoporous carbon sheets derived from watermelon peel via deionization capacitors. RSC Adv. 2017, 7, 4297-4305. [CrossRef]

24. Engineering ToolBox. Relative Permittivity—the Dielectric Constant. 2010. Available online: https://www.engineeringtoolbox. com/relative-permittivity-d_1660.html (accessed on 6 August 2021).

25. Khan, T.A.; Nazir, M.; Khan, E.A.; Riaz, U. Multiwalled carbon nanotube-polyurethane (MWCNT/PU) composite adsorbent for safranin $\mathrm{T}$ and $\mathrm{Pb}(\mathrm{II})$ removal from aqueous solution: Batch and fixed-bed studies. J. Mol. Liq. 2015, 212, 467-479. [CrossRef]

26. Pourbaix, M. Atlas of Electrochemical Equilibria, 2nd ed.; National Association of Corrosion Engineers: Houston, TX, USA, 1974; pp. 436-442.

27. Nowotny, J.; Alim, M.A.; Bak, T.; Atanacio, A.J.; Malik, A. Electrical properties and defect chemistry of indium-doped TiO 2 . Thermoelectric power. Ionics 2015, 21, 2019-2029. [CrossRef]

28. Nowotny, J.; Bak, T.; Ionescu, M.; Alim, M.A. Electrical Properties and Defect Chemistry of In-Doped TiO 2 in Terms of the Jonker Formalism. J. Phys. Chem. A 2015, 119, 4032-4040. [CrossRef] [PubMed]

29. Atanacio, A.J.; Alim, M.A.; Bak, T.; Ionescu, M.; Nowotny, J. Segregation in Titanium Dioxide Co-Doped with Indium and Niobium. J. Am. Ceram. Soc. 2017, 100, 419-428. [CrossRef] 